\title{
Growth, flowering and fruit-set of the tomato at high temperature $^{1}$
}

\author{
A. A. Abdalla and K. Verkerk \\ Department of Horticulture, Faculty of Agriculture, University of Khartoum, Sudan; \\ Department of Horticulture, Agricultural University, Wageningen, The Netherlands
}

Received 25 August, 1967

\section{Summary}

Tomato yields under the high summer temperatures and low humidity in the Sudan are very unsatisfactory. Research at the Department of Horticulture at Wageningen, comparing the effect of high temperature of $35^{\circ} \mathrm{C}$ day and $25^{\circ} \mathrm{C}$ night with normal temperature of $22^{\circ} \mathrm{C}$ day and $18^{\circ} \mathrm{C}$ night showed that under the first temperature conditions stem growth was twice as fast, giving thin stems and many trusses with weak flowers, while in many cases styles were as long or even longer than the stamen tube; flower shedding was remarkedly increased and only half the number of fruits developed at the first two trusses. Pollen germination in vitro is best at $27^{\circ} \mathrm{C}$, but tube growth of pollen from high temperature is slower than from normal temperature while pollen from shed flowers gave practically no germination and tube growth. Pollen counts on the stigma showed only very limited amounts of pollen at high temperature compared to the normal one.

\section{Introduction}

In the arid tropical region of the Sudan the high summer temperatures and the low humidity limit the production of tomato to the cooler part of the year. To extend the season of production it is necessary to know the nature of the growth, flowering and fruiting of the plant in relation to these summer conditions. Preliminary studies under the hot arid conditions of the Sudan indicated that the problem lies in vine growth, flower shedding and failure of fruit-set, possibly because of lack of pollination due to the marked extension of styles and/or weakness of pollen. Investigations into the viability and effectiveness of pollen produced at high temperature are required for the proper evaluation of flowering and fruiting. The inadequacy of information pertinent to the hot arid conditions of the Sudan prompted this study at the Department of Horticulture at Wageningen.

1 This article will also be published as Publication 299, Laboratorium voor Tuinbouwplantenteelt, Landbouwhogeschool, Wageningen, The Netherlands. 


\section{Methods and results}

Growth, flowering and fruiting

Seedlings of Fireball, Hot Set and Porter were raised in flats in a glasshouse kept at approximately $22^{\circ} \mathrm{C}$ day and $18{ }^{\circ} \mathrm{C}$ night temperature during the period March till May. When the seedlings were four weeks old, they were transplanted singly into 12 inch plastic pots. Fifteen plants of each of the three cultivars were transferred to a glasshouse kept at appr. $35^{\circ} \mathrm{C}$ day and $25^{\circ} \mathrm{C}$ night temperatures, imitating summer conditions at the Sudan. Another fifteen plants were kept in a glasshouse at appr. $22^{\circ} \mathrm{C}$ day and $18{ }^{\circ} \mathrm{C}$ night temperatures, more normal for tomato growing in Holland and serving as the control. These two sets of temperatures are hereafter referred to as high and normal. The relative humidity of the high temperature glasshouse was checked periodically. The plants were watered daily. No pruning took place, so all the side shoots remained on the plants. The stem lengths of five plants were measured weekly for a period of three weeks and the mean growth per day was calculated. Time taken from seeding to the appearance of the flower buds, numbers of flowers in the first and second trusses, numbers of shed flowers and fruits formed were recorded. Data were also taken on the time for flower buds to open and time from anthesis to noticible fruit development.

Table 1 shows that the growth rate of the stem in $\mathrm{mm}$ per day at high temperature is about double the value of that at normal temperature, resulting in long and thin stems and side branches compared to the control. Many more trusses were visible after ten weeks at high than at normal temperature, because side branches also formed trusses remarkedly fastly. Not mentioned in the table is that the flower parts were smaller and weaker at high than at normal temperature. At high temperature flower buds became visible about 30 days from seeding, while it took about 42 days at normal temperature conditions. This holds true for all three cultivars. Time elapsing between anthesis and noticible fruit development as well as to ripe fruit was much shorter under high than under normal temperature. In addition, at high temperature many styles were of the same length as the stamens or even extending beyond the stamen tube. The latter case was more frequent in Porter than in the other cultivars. Browning and drying of the tip of the stamen tube was frequently found at the high temperature in all three cultivars.

The number of flowers per truss produced at high temperature was fairly comparable to that produced by plants growing under normal temperature. Differences among the three cultivars are neglectable (Table 1). Flower shedding was markedly increased by the high temperature. Flowers that shed show a yellowing pedicel and later wither and drop. More shedding was observed in the later flowers of a truss than in the first few. In Fireball and Hot Set many non-shed flowers failed to produce fruits. The flowers remained attached to the truss and had shrivelled ovaries that remained dormant.

In most of the cases fruits developed only from the first and second flowers of the truss. Fruits formed under high temperatures ranged between 1 and 3 per truss, while under normal temperature fruit yield ranged between 3 and 6 fruits per truss.

Germination of pollen and pollen tube growth at different temperatures in vitro Fresh pollen was collected from fully open flowers using an artificial bee (Wellensiek, 1948). Pollen was germinated in small tubes in a medium of $5 \%$ sucrose in $100 \mathrm{ppm}$ boric acid. This medium proved to be optimal for tomato pollen germina- 
GROWTH, FLOWERING AND FRUIT-SET OF THE TOMATO AT HIGH TEMPERATURE

Table 1 Characters of Fireball (Fb), Hot Set (HS) and Porter (P) at high and normal temperature

\begin{tabular}{|c|c|c|c|c|c|c|c|c|}
\hline & \multicolumn{4}{|c|}{ High temperature } & \multicolumn{4}{|c|}{ Normal temperature } \\
\hline & $F b$ & $H S$ & $P$ & Mean & $F b$ & $H S$ & $P$ & Mean \\
\hline Stem growth rate in $\mathrm{mm} /$ day & 35.0 & 40.5 & 41.3 & 38.9 & 18.2 & 22.3 & 23.2 & 21.2 \\
\hline No trusses in 10 weeks & 10.5 & 10.0 & 9.6 & 10.0 & 4.0 & 2.0 & 2.0 & 2.7 \\
\hline $\begin{array}{ll}\text { truss } & 1 \\
\text { truss } & 2\end{array}$ & $\begin{array}{l}6.5 \\
4.6\end{array}$ & $\begin{array}{l}6.3 \\
5.0\end{array}$ & $\begin{array}{l}7.8 \\
5.6\end{array}$ & $\begin{array}{l}6.9 \\
5.1\end{array}$ & $\begin{array}{l}7.0 \\
6.6\end{array}$ & $\begin{array}{l}6.4 \\
4.4\end{array}$ & $\begin{array}{l}6.7 \\
5.0\end{array}$ & $\begin{array}{l}6.7 \\
5.3\end{array}$ \\
\hline $\begin{array}{ll}\text { Shed flowers: } & \text { truss } 1 \\
& \text { truss } 2\end{array}$ & $\begin{array}{l}2.0 \\
1.2\end{array}$ & $\begin{array}{l}3.0 \\
1.8\end{array}$ & $\begin{array}{l}4.5 \\
3.0\end{array}$ & $\begin{array}{l}3.2 \\
1.9\end{array}$ & $\begin{array}{l}0.5 \\
0.8\end{array}$ & $\begin{array}{l}0.7 \\
0.5\end{array}$ & $\begin{array}{l}2.2 \\
1.5\end{array}$ & $\begin{array}{l}1.1 \\
0.9\end{array}$ \\
\hline $\begin{array}{l}\text { truss } 1 \\
\text { truss } 2\end{array}$ & $\begin{array}{l}2.0 \\
1.2\end{array}$ & $\begin{array}{l}1.5 \\
1.0\end{array}$ & $\begin{array}{l}2.5 \\
1.5\end{array}$ & $\begin{array}{l}2.0 \\
1.2\end{array}$ & $\begin{array}{l}4.2 \\
3.5\end{array}$ & $\begin{array}{l}3.7 \\
3.0\end{array}$ & $\begin{array}{l}4.0 \\
1.5\end{array}$ & $\begin{array}{l}4.0 \\
2.7\end{array}$ \\
\hline
\end{tabular}

tion after a series of tests of different concentrations were made. Hanging drops of the medium containing the pollen were tested under the microscope after five hours at $22,27,34$ and $42^{\circ} \mathrm{C}$. Five drops from each treatment were examined for pollen germination and five series were made. For counting germinating pollen, fields for counts were chosen at random and in each case a minimum of 100 grains were examined. An ocular micrometer was used for the measurement of the length of the pollen tubes, 24 and 28 hours after the beginning.

Pollen from flowers that will shed, so from flowers showing yellowing pedicels, was examined in the same manner.

Germination of pollen was evident already after 2 hours and pollen tubes were clearly developed after 5 hours. Pollen grains were counted as germinated when the protrusion of the tube was more than $0.5 \mathrm{~mm}$.

The percent germination of pollen and pollen tube growth at the different temperatures are shown in Table 2. For fresh pollen produced at high or at normal temperature, the temperature most suitable for pollen germination was near $27^{\circ} \mathrm{C}$. Higher temperatures retard both pollen germination and pollen tube growth.

At $42{ }^{\circ} \mathrm{C}$ no pollen germination was detected and shrunk and ruptured grains were frequent. Very few pollen grains showed detectable protrusions which failed to develop into measurable tubes. Pollen produced by non-shed flowers at high temper.ature gave a percentage of germination similar to pollen produced under normal

Table 2 Pollen germination and tube growth in vitro at different temperatures of pollen from flowers produced at high $(H)$ or normal $(N)$ temperature and of shed flowers $(S)$

\begin{tabular}{|c|c|c|c|c|c|c|c|c|c|}
\hline \multirow{2}{*}{$\begin{array}{l}\text { Germination } \\
\text { at }{ }^{\circ} \mathrm{C}\end{array}$} & \multicolumn{3}{|c|}{$\%$ germination after $5 \mathrm{hr}$} & \multicolumn{6}{|c|}{ Tube length in $\mathrm{mm}$ after 24 and $48 \mathrm{hr}$} \\
\hline & $H$ & $N$ & $S$ & \multicolumn{2}{|c|}{$H$} & \multicolumn{2}{|c|}{$N$} & \multicolumn{2}{|c|}{$S$} \\
\hline $22^{\circ}$ & 63 & 60 & 0 & 2.8 & 5.6 & 3.7 & 5.2 & 0.0 & 0.0 \\
\hline $27^{\circ}$ & 69 & 67 & 5 & 3.6 & 5.8 & 6.1 & 7.5 & 3.0 & 4.5 \\
\hline $34^{\circ}$ & 42 & 55 & 3 & 3.0 & 4.0 & 3.6 & 5.5 & 3.3 & 4.0 \\
\hline $42^{\circ}$ & 0 & 0 & 0 & 0.0 & 0.0 & 0.0 & 0.0 & 0.0 & 0.0 \\
\hline
\end{tabular}


temperature. The growth of the pollen tubes of the high temperature pollen was slower however.

Pollen from shed flowers failed to germinate at 22 and $42^{\circ} \mathrm{C}$. Only negligible percentages of germination were obtained at the other temperatures. Tube growth of this pollen was extremely poor.

\section{Pollen on the stigma}

Styles of flowers that had been fully open for 3 days were removed, fixed and prepared for examination in ultra violet light under the fluorescence microscope. The styles were placed in FAA for at least half an hour, washed and put in $8 \mathrm{~N}$ sodium hydroxide for another hour, then washed again and emersed in 0.1 percent anilin blue in $0.1 \mathrm{~N} \mathrm{~K}_{3} \mathrm{PO}_{4}$ overnight. The styles were put on slides, covered and pressed gently.

Counts of pollen grains landing on the stigmatic surface were made. Ten flowers from plants grown at each of the two temperatures were examined. On the high temperature plants the number of pollen grains was remarkably low, except for one flower, where it was 17 . Countings for the plants at the normal temperature, however, resulted in 6-165 pollen grains per stigma, with an average of 63. A good portion of this normal temperature pollen had already extended thin tubes inside the ovary.

Growth of the pollen tube in the style

Flowers that had just opened were emasculated, embagged and hand pollinated the following day. Indicator flowers were marked, so that the test flowers were hand pollinated at the time when they started reflexing their petals. Pollen from plants grown at normal temperature was used to pollinate plants grown at the same temperature and plants grown at the other temperature. The same was repeated with high temperature pollen. Fresh pollen was used and the pollinated styles with the ovaries attached were removed after 6,24 or 48 hours from the time of pollination. The average length of the style was $8.5 \mathrm{~mm}$. Fresh pollen produced at high or normal temperature gave a high percentage of germination and tubes which penetrated down to the ovary in 24 hours, except that pollen produced at high temperature and used for pollination at normal temperature failed to produce pollen tubes in 7 out of 10 observations and the few that were produced failed to reach the ovary after 48 hours.

\section{Reciprocal pollen transfer and fruit set}

Reciprocal hand pollinations of flowers from high and normal temperatures were made as well as hand pollinations within both temperatures. Fruits resulting from these hand pollinations were counted. Table 3 gives the different self pollinations and crosses made and the numbers of fruits resulting. Maximum fruit set was obtained when pollen was used on plants growing at the corresponding temperatures. High temperature pollen used on normal temperature plants gave a very poor set. Normal temperature pollen on high temperature plants gave intermediate results.

\section{Discussion}

It has long been known that high temperatures in tomato production, usually above $30^{\circ} \mathrm{C}$, cause blossom drop and failure of fruit set. Smith (1932) reported high tem- 
Table 3 Artificial selfing and cross pollinations between flowers from high and normal temperatures

\begin{tabular}{cccc}
\hline $\begin{array}{c}\text { Source of pollen } \\
\text { (temperature) }\end{array}$ & $\begin{array}{c}\text { Growing- } \\
\text { temperature } \\
\text { of flowers } \\
\text { pollinated }\end{array}$ & $\begin{array}{c}\text { Number of } \\
\text { flowers } \\
\text { pollinated }\end{array}$ & $\begin{array}{c}\text { Number of } \\
\text { fruits }\end{array}$ \\
high & high & 19 & \\
normal & normal & 20 & 14 \\
high & normal & 17 & 17 \\
normal & high & 21 & 4 \\
\hline
\end{tabular}

perature as a significant factor contributing to blossom drop. Reasons for this physiological phenomenon are many and diverse. They include viability and effectiveness of pollen produced at high temperature rate of pollen tube growth, drying of the style, extension of the style beyond the stamen tube resulting in lack of pollination and rapid disintegration of the embryo sac. Quantity of pollen produced, liberation of pollen to the stigma and pollen tube growth at high temperatures received little attention.

There is pronounced distribution of the available substrate among the demanding tissues of the plant resulting in insufficient assimilates for the optimal development of all the different organs of the plant at high temperatures. Verkerk (1955) reported less mean dry weight of $1 \mathrm{~cm}$ pieces of stems at high temperature compared to normal temperature, while trusses were even more reduced. Hence optimal flower size was often not maintained and usually only the first few flowers of the first two trusses developed into fruits. High temperature caused drying and browning of the stamen tips and no fruits were formed. This is possibly due to dry unfunctional pollen or the lack of release of pollen to the stigma. High temperature induced elongation of the style and in such cases only after hand pollinations fruits could be obtained. Extension of style, which is frequent under the hot arid conditions of the Sudan, was not as frequent under the less arid conditions of this experiment. In Fireball and Hot Set many ovaries were shrivelled and remained dormant. Whether these ovaries had fertilized ovules has not been investigated. Johnson and Hall (1953) spoke of dormant fertilized ovaries in plants grown under low light intensity and low or high temperatures.

Pollen germination in vitro at different temperatures indicated that the optimum for germination and tube growth is about $27^{\circ} \mathrm{C}$. Pollen tubes produced in vitro at this optimal temperature are similar in length to those growing in the style, so to reach the ovules and bring about fertilization. At higher temperature, around $34{ }^{\circ} \mathrm{C}$, fresh mature pollen will germinate satisfactorily, but the tube growth is slow. Pollen failed to germinate at $42^{\circ} \mathrm{C}$.

Pollen collected from flowers destined to shed at high temperature was very poor at all temperatures. This failure to germinate and produce normal tubes is possibly due to the severe inadequacy of substrate required for these processes. When these shedding flowers were hand pollinated, they failed to produce fruits. It seems that failure to fruit is not only attributed to pollen, but that the pistil is also involved. Sugiyama et al. (1966) reported that flower buds 9-5 days before anthesis and flowers 1-3 days after anthesis are the most susceptable to high temperatures, possibly be- 
cause of the degeneration of pollen tetrads before and the harmful effect on fertilization and the fertilized eggs after anthesis. Further on they found degeneration of macrospores in ovules treated with high temperature for 15 hours given at three hour intervals per day.

No precise quantitative method was devised to determine the amount of pollen produced at high and normal temperatures. Vibration by means of an artificial bee showed far more pollen produced at normal temperature than at high. Although this method could be misleading, also the experience from hand pollinations pointed towards less pollen produced at high temperature than at normal. However, the amount of pollen liberated to the stigma was definitely less at high than at normal temperature. Examination of landing of pollen grains on the stigmatic surface revealed this fact.

Viable pollen produced at high temperature germinated well on the stigma, but growth of the pollen tube down the style was rather slow when compared to normal temperature pollen. The retarded rate of growth of the tubes of pollen produced at high temperature may be due to inadequate food stored in the pollen grain. Brink (1924) stated that the growth of the pollen tube is causally related to the digestion of the food substrate within the tube. Hand pollination using high and normal temperature pollen on plants grown at high and normal temperature reveals that although pollen produced at high temperature is viable, its effectiveness in producing fruits does not match that of normal temperature pollen. The reason for failure of high temperature pollen to produce fruits in many crosses at the normal temperature is not clear.

\section{References}

Brink, R. A., 1924. The physiology of pollen. I. The requirements for growth. Am. J. Bot. 11 : 218-228.

Johnson, S. P. and Hall, W. C., 1953. Vegetative and fruiting responses of tomatoes to high temperature and light intensity. Bot. Gaz., $114: 449-460$.

Smith, O., 1933. Relation of temperature to anthesis and blossom drop of the tomato together with a histological study of the pistils. J. Agric. Res., 44 : 183-190.

Smith, O. and Cochran, H. L., 1935. Effect of temperature on pollen germination and tube growth in the tomato. Cornell Univ. Agric. Exp. St. Mem., 175.

Sugiyama, T. et al., 1966. Effect of high temperature on fruit setting of tomato under cover. Acta Horticulturae, 4 : 63-69.

Verkerk, K., 1955. Temperature, light and the tomato. Meded. Landb. Hogesch., Wageningen, 55, $175-224$.

Wellensiek, S. J., 1948. Een kunstmatige bloembestuiver (An artificial pollinator). Meded. Dir. Tuinb., 11: 101-104. 